\title{
An Evaluation on Various Software Component based Selection Techniques
}

\author{
Shikha Bansal \\ CSE Department, GTBIT, IP University, Delhi, India
}

\begin{abstract}
Component Based Software Engineering (CBSE) works on the principle of reusing a software. It helps in evolving the bigger software by merging the previously available module. In CBSE, examining \& selection of module is a very difficult task but it is important to know how effectively software module is reusable. This paper analyze the component selecting technique based on the criteria namely:-WSM, AHP \& HKBS . AHP and WSM both are already used for reviewing and selecting the module but HKBS is a recently developed technique for selecting the module. Every technique have its own restrictions and advantages. Comparing these three techniques of component selection shows that HKBS is better than AHP \& WSM. Previous results of achievement and failure helps to achieve the required result and also reduces time of selection of the module that can be reused effectively.
\end{abstract}

Keywords: Component Off The Shelf, Analytical Hierarchical Processing, Component Based Software Engineering, Open Source Software Product(OSSP),Hybrid Knowledge Base System, Weighted Score Method, Multiple Crtiterian Decision Making

\section{INTRODUCTION}

A component is the module or part that carries out different tasks freely. It also merges with other modules by the using middleware. Middleware represents a mutual connection between modules. CBSE [1] work is to form the system by utilizing already available modules so as to increase there efficiency. Merging modules is less time consuming as compared to implimentation of each module. CBSE institutes philosophy of obtaining rather than build[2] . For eg: if we want to create a car engine, then instead of creating each hardware, we just use the hardware which was created earlier. The objective is to provide same benefit to the users who uses that $\mathrm{s} / \mathrm{w}$ either for longer time period or shorter time period. CBSD[3] provide significance on reuse of the previously advanced CTOS( Component Off The Shell) modules to create the system. Before merging the module, their functionalities should be analysed whether they are in accordance of our use or not. If it is satisfactory one then buy that, or else other module will be checked in comparision of previous one. Criteria Based Selection is the standard, level or degree by which module is selected or analysed. It is used as a means to make sure that the best module is used by attaining all the criterian requirements. Selection of module is long and composite procedure. By appropriate use of previous knowledge[4] we can utilise CBR in selecting the module. Surveying and selection of the module consists of concurrent examination of different elements to rank the accessible modules and selecting the required one. This is MCDM[5] technique in which different decision have to be made over different criteria. The goal of CBSE is to save the cost and time of development of a large system, outcome should be efficient and reliable, no errors etc. The complication arises with the COTS [6,7]components is that user have limited connection with the internal design of product.

\section{FEATURES OF CBSE PROCESS MODEL}

To get the benefit, it is necessary to carefully select the component. It is a complex task but this technique helps in selecting the best module from different available modules. This process of selection[6] includes 5 steps :

- Evaluate:- This states the comprehensive specification of system and verifying the different functions of modules that are available from various providers..

- Selecting the module:-In this step, module will be selected to reach the desired goal. If the selected module is satisfactory, in future effort made for selection of module will be less.

- Adaptation:-To make sure that dissension between module functionalities is less, diverse techniques are utilized to make a obstruction for unwanted functionalities.

- Integrate:-In this step, gross activities performed are merged into a single unit and then that unit will be tested. 
- Update:- After performing the tests, all incorrections will be rectified, if any latest version of a software is available, then it will be upgraded as per the requirement of the user.

Even a small alteration in the module can upset the total performance of system, For the advantage of user, appropriate prepration must be done before selecting the module. It is a complex part to select the appropriate module among different modules available and to enhance trust on the module selected. In section 2, it explains a few software component based techniques, section 3 explains comparison between three techniques and section 4 explains conclusion and future work .

\section{COMPONENT BASED SELECTION TECHNIQUES}

\section{A. Weighted Score Method(WSM)-}

It [8]is the primeval search process that is utilised to select the module required for the project by the user. This process is used in cases where different criteria and different modules $\left(M_{1}, M_{2}, \ldots \ldots . . M_{n}\right)$ are accessible.

WSM[5] uses step by step method for selecting the best modules.

- Decide norms for selecting the best modules.

- Assign weights (W) and scores (S) to available modules that shows their significance.

- Multiplying of Weights(W) and Scores(S) will be done.

- Module will be selected on the basis of weight. The greater the weight, more the module will be appropriate for selection.

WSM[9] is calculated by using the expression:-

$$
\mathrm{S}\left(\mathrm{A}_{\mathrm{i}}\right)=\sum \mathrm{W}_{\mathrm{j}} \mathrm{S}_{\mathrm{ij}}
$$

In this, $W_{j}$ is the ${ }^{\text {th }}$ criteria weight and $S_{i j}$ is the score that classifies performance of Ai over criteria $(C j)$.

This one example states the complete process of WSM. The uber services have 4 criteria( Pool, uberGO , uberHIRE, uberXL) in regard of 5 modules(i.e A, B, C, D, E). For the end score, we multiply the value of each module with the weight and divide it by total weight as shown in Table1.

\begin{tabular}{|l|c|c|c|c|c|c|}
\hline \multicolumn{1}{|c|}{ Criteria } & Weights & A & B & C & D & E \\
\hline Pool & 10 & 3 & 2 & 3 & 5 & 3 \\
\hline uberGO & 5 & 6 & 2 & 1 & 4 & 1 \\
\hline uberHIRE & 20 & 1 & 4 & 2 & 3 & 6 \\
\hline uberXL & 15 & 2 & 6 & 8 & 2 & 5 \\
\hline Final Score & $50(W)$ & 2.2 & 4 & 3.9 & 3.2 & 4.6 \\
\hline
\end{tabular}

Table 1

In the above shown illustration, all the modules has score less then E, therefore it shows that $\mathrm{E}$ is most suitable..

WSM has its own advantages and disadvantages:-

Advantages:-it is a process based on numerics and from calculation point of view it is quite easy to perform.(2)This process can be utilized by both a group of people as well as an individual. Disadvantages:-This process is not applicable when number of modules available are larger, as this process is used when only a little or a limited number of modules are available. 
This process [9] gives the solution of complex situations. In 1970's this process was made known by Thomas L. Saaty. In different fields, this process is utilized. This process make use of reliant way and it also uses distinctive thinking and perceptions for taking an productive decision.

In the method of AHP [10,11], the objective is positioned on the top then the objective is divided into sub-objectives like a tree hierarchy. And then, the criteria to achieve the objective are decided and lastly given modules will be ranked in accordance to their significance.

Example of AHP:-

1. Let us assume that, we have 5 criteria (OSSP) out of which selection has to be done, and its choosen characteristics (i.e. performance, cost, testing) and then state their significance over one another[12].

For eg: the cost is thrice as significant as performance and testing is twice as significant than cost. According to the significance, construct the matrix :-

$$
\mathrm{M}=\quad \mathrm{X}\left(\begin{array}{ccc}
\mathrm{X} & \mathrm{Y} & \mathrm{Z} \\
1.0000 & 0.3333 & 2.0000 \\
3.0000 & 1.0000 & 0.5000 \\
0.5000 & 2.0000 & 1.0000
\end{array}\right)
$$

2. Multiplying the matrix in (M X M) form, compute the eigen vector by summing each row and row totals.

$$
\left.\mathrm{M}=\quad \begin{array}{ccc}
2.9998 & 4.6600 & 4.1640 \\
6.2500 & 2.9988 & 7.0000 \\
7.0000 & 4.2648 & 3.0000
\end{array}\right)
$$

Lastly, to get the eigen vector and organize it we divide each row sum by total row sum as shown in matrix 2

$$
\begin{aligned}
& \mathrm{X} \\
& \mathrm{Y}
\end{aligned}\left(\begin{array}{c}
0.2792 \\
0.3837 \\
0.3369
\end{array}\right)
$$

Matrix 2

3. For the second eigen vector, we multiply (Mx M) matrix and rest of process will be same as performed previously. So, we get our second eigen vector as shown in matrix 3.

$$
\begin{aligned}
& \mathrm{X} \\
& \mathrm{Y} \\
& \mathrm{Z}
\end{aligned}\left(\begin{array}{l}
0.2792 \\
0.3837 \\
0.3369
\end{array}\right)
$$

Matrix 3

Since, both eigen vector values are nearly similar to each other, we stop here only. With this illustration, it is expressed that Firstly cost is more significant then testing and then third is performance.

4. To rank these, we examined that for each OSSP, we computed the related exterior matrix as stated in table 4. 


\begin{tabular}{|c|c|c|c|}
\hline & $\mathrm{X}$ & $\mathrm{Y}$ & $\mathrm{Z}$ \\
\hline $\begin{array}{c}\text { OSSP } \\
\mathrm{P}\end{array}$ & 0.3679 & 0.5136 & 0.2133 \\
\hline $\begin{array}{c}\text { OSSP } \\
\mathrm{Q}\end{array}$ & 0.5824 & 0.4532 & 0.3521 \\
\hline $\begin{array}{c}\text { OSSP } \\
\mathrm{R}\end{array}$ & 0.1237 & 0.9218 & 0.2387 \\
\hline $\begin{array}{c}\text { OSSP } \\
\mathrm{S}\end{array}$ & 0.4126 & 0.2881 & 0.4534 \\
\hline $\begin{array}{c}\text { OSSP } \\
\mathrm{T}\end{array}$ & 0.8321 & 0.1217 & 0.3166 \\
\hline
\end{tabular}

Table 4

By multiplying Table 4 with second eigen vector Matrix 3, we will get the final ranks as shown in Table 5 .

\begin{tabular}{|c|c|c|}
\hline & Multiplication & Rank \\
\hline $\begin{array}{c}\text { OSSP } \\
\mathrm{P}\end{array}$ & 0.9720 & 5 \\
\hline $\begin{array}{c}\text { OSSP } \\
\mathrm{Q}\end{array}$ & 0.4573 & 2 \\
\hline $\begin{array}{c}\text { OSSP } \\
\mathrm{R}\end{array}$ & 0.4641 & 1 \\
\hline $\begin{array}{c}\text { OSSP } \\
\mathrm{S}\end{array}$ & 0.3787 & 4 \\
\hline $\begin{array}{c}\text { OSSP } \\
\mathrm{T}\end{array}$ & 0.3926 & 3 \\
\hline
\end{tabular}

Table 5

This table shows the ranking of the modules. First is OSSP R, second is OSSB Q, third is OSSP T and so on.

AHP has advantages and disadvantages:-

Advantages : It presents a clear view for decision process and make use of eigen value for ranking of modules.

Disadvantages: Addition and elemination of modules occasionaly muddle their ranking, its computation is much time consuming.

\section{HYBRID KNOWLEDGE BASE SYTEM(HKBS) -}

In HKBS[13] Method, knowledge base(KB) are computer processes that saves authorized knowledge and utilize it to give the solution of the problems. KB comprises of two modules: knowledge base and inference engine. $\mathrm{KB}$ assists the decision engineer in inspection and selection of module. It composites the knowledge and supplies a tool that assists decision engineer in inspection and selection of module. Software module is choosed by merging two techniques i.e. CBR and RBR. Rule based reasoning is an unorganised approach in which answers of the problem is provided by human specialists using knowledge base. Case based reasoning is a organised approach in which answer of the problem is clarified with the help of previous knowledge .

This approach was developed by Intelligent System Development and solution was brought in by Sonar in 2004 \& 2007. HKBS[11,12] makes use of blend of rule based and case based approach for the improved solution of the problem. Following figure shows HKBS approach: 


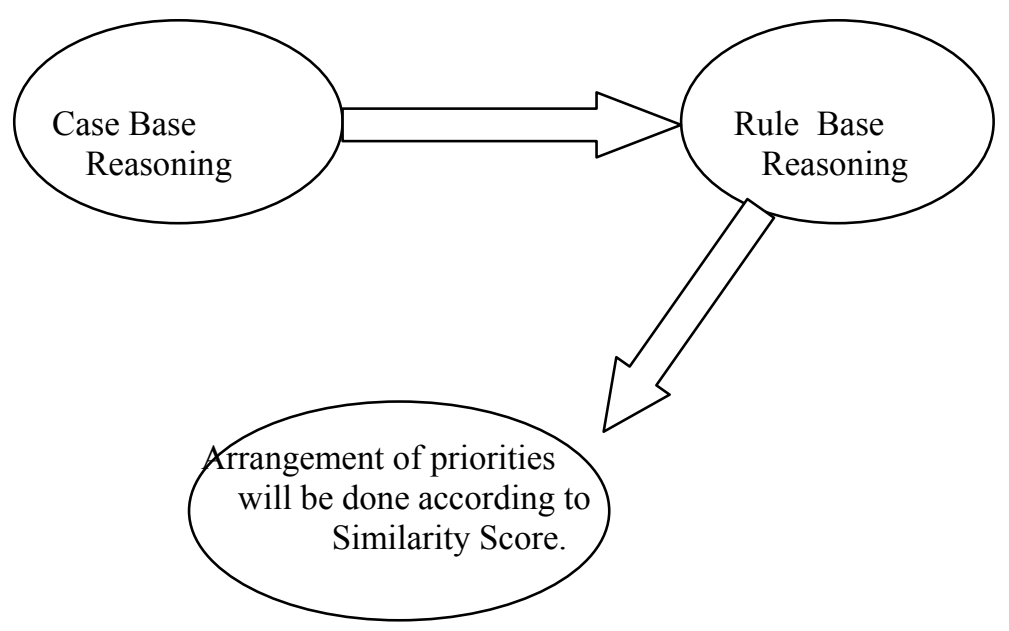

Figure:1

In this Process, RBR assists decision engineer to: -

- To decide the criteria for inspecting the modules.

- Collecting the user necessities for the module by utilizing details and knowledge the person have.

- Evolve the problem case.

After collecting the necessities of the user, these necessities are entered as input data to the CBR which then gives the output.

Then CBR helps in:-

- Correlating user necessities of module with the reasoning of the selected module that was saved earlier in the CBR as Cases.

- Resaving those modules which are nearly related to the user necessities of module and then accordingly prioritize them.

HKBS[13] is computed by using this formula:

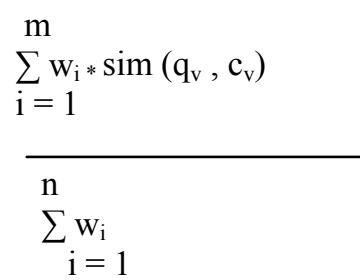

In this, $\mathrm{Wi}$ is similarity estimate weight and $\operatorname{sim}(\mathrm{qv}, \mathrm{c} v$ ) is the similarity values of problem and case. Similarity score states how efficiently user requirements of module are met with candidate module .

The single similarity outcome is computed by using the formula:-



HKBS has its own advantages and disadvantages:- 
Advantages : - This process is appropriate for both larger or smaller number of modules.(2) Addition or elemination of modules does not need much effort for performing the inspection again. (3) It states whether the choosen module is in accordance to user necessities. Disadvantages:- Searching the related case from knowledge base takes a lot of time and effort. (2) Previous cases that are saved earlier does not gives the idea of new technologies that we can utilize now for selecting the module.

HKBS is more efficient than AHP and WSM.

\section{DIFFERENCE BETWEEN AHP,WSM \& HKBS}

The differentiation between these three of the methods reveals that HKBS is more desirable than AHP and WSM. Assessing Efficiency:

- $\quad$ HKBS performs better as subjective as well as an objective measure.

- HKBS doesn't need much effort

-If provided figure of modules raises for evaluation purpose

-If differences occurs in the needs of user.

-To rank the module that can be used again efficiently.

- HKBS also assesses that if the choosen module is in accordance to the requirements of the user or not.

Reutilizing Experience:

- Matching cases which are saved previously serves as experience and knowledge which can be used again for selection and assessment of the efficient module.

Ranking Result:

- AHP and WSM presents the complimentary ranking of the module where as HKBS presents the final outcome as well as states how efficiently module fulfil the requirements of the user.

- Addition and elemination of software module is comparatively simple task in HKBS as needs of user module details are already saved in case base.

\begin{tabular}{|c|c|c|c|}
\hline Analyzing Modules & AHP & WSM & HKBS \\
\hline Subjective Measures & $\sqrt{ }$ & $\mathrm{X}$ & Less effort \\
\hline $\begin{array}{c}\text { If the No. of modules } \\
\text { for analysis increases }\end{array}$ & $\begin{array}{c}\text { Comparision have to be } \\
\text { made again }\end{array}$ & $\begin{array}{c}\text { Ranking be done again } \\
\text { after analyzing the } \\
\text { criteria }\end{array}$ & Less effort \\
\hline Any alternation & $\begin{array}{c}\text { Comparision have to be } \\
\text { made again }\end{array}$ & Less effort & $\sqrt{ }$ \\
\hline $\begin{array}{c}\text { Reuse } \\
\text { Knowledge }\end{array}$ & $X$ & $X$ & X \\
\hline Ranking Problem & $\sqrt{ }$ & $X$ & $\sqrt{ }$ \\
\hline Objective measures & $\mathrm{X}$ & $\mathrm{X}$ & \\
\hline User Need & & & \\
\hline
\end{tabular}

\section{CONCLUSIONS}

1. The presented paper states a few component based selection (CBSE) approach like WSM, AHP\& HKBS. Every approach has its own Advantages and Disadvantages.

2. If one techniques handles a limited/small amount of modules then other one can support a large/greater amount of modules. Neither of them is satisfactory for every available case. The upcoming scope is to 
create a approach that can supply most appropriate solution for all the modules available and also appropriate for each and every case.

\section{REFERENCES}

[1] Harshpreet Singh. Quantifying COTS Components Selection using Multi Criteria Decision Analysis Method Global Journal of Computer Science and Technology: Software \& Data Engineering. Global Journals Inc. (2014).

[2] Kaur, Arvinder, and Kulvinder Singh Mann. "Component selection for component based software engineering." International Journal of Computer Applications 2.1 (2010): 109-114

[3] Divya Chaudhary, Rajender Singh Chhillar, Component Based Software Engineering Systems: Process and Metrices, International Journal of Advanced Research in Computer Science and Software Engineering(2013).

[4] Ardhenu Mandal, S.C.Pal, Emergence of Component Based Software Engineering, International Journal of Advanced Research in Computer Science and Software Engineering(2012).

[5] A. Mohamed ,T.Wanyama, ,G.Ruhe, A.Eberlein, Far,COTS Evaluation supported by knowledge base, Springer-Verlag, LSO 2004 LNCS 3096.

[6] Feras Tarawneh, Fauziah Baharom, Jamaiah Hj. Yahaya, and Faudziah Ahmad, Evaluation and Selection COTS Software Process: The State of the Art, IJNCAA(2011)

[7] Thomas Neubauer, Interactive Decision Support for Multiobjective COTS Selection, IEEE(2007).

[8] Syed Ahsan Fahmi and Ho-Jin Choi, A Study on SoftwareComponent Selection Methods, ICACT( 2009).

[9] Anil Jadhav, Rajendra Sonar, Analytic Hierarchy Process (AHP), Weighted Scoring Method (WSM), and Hybrid Knowledge Based System (HKBS) for Software Selection: A Comparative Study, Second International Conference on Emerging Trends in Engineering and Technology, ICETET(2009).

[10] D.Morera ,COTS evaluation using desmet methodology \& Analytical Hierachical Processing (AHP), Springer- Verlag,PROFES ,2002.

[11] T.L, Saaty, The Analytical Processing,McGraw hill,1980.

[12] Rafa E. AL-Qutaish \& Mohannad I. Muhairat,The Analytical Hierarchy Process as a Tool to Select

[13] Open Source Software, $8^{\text {th }}$ WSEAS International conference on software engineering.

[14] Anil S. Jadhav, Rajendra M.Sonar, A Hybrid knowledge based system approach, The Journal of Systems and Softwares 84(2011)1394-1407

[15] Loveleen Kaur \& Dr. Hardeep Singh, Software Component Selection techniques - A review, International Journal of Computer Science and Information Technologies(IJCSIT). 